\title{
A CRISE ATUAL E O DEBATE INSTITUCIONAL
}

http://dx.doi.org/10.25091/

So101-3300201700030008
FERNANDO LIMONGI*

Argelina Cheibub Figueiredo**

\section{RESUMO}

$\mathrm{O}$ artigo discute a recente crise política brasileira. A crise reabriu o debate institucional, levando um retorno às teses que veem na combinação entre presidencialismo e multipartidarismo a raiz de todas as crises políticas experimentadas pelo país. O artigo critica essa interpretação, retomando a produção acadêmica dos últimos anos que aponta para a capacidade do sistema brasileiro em produzir decisões. Como conclusão, o artigo chama atenção para a importância das estratégias políticas na conformação da crise política atual.

PALAVRAS-CHAVE: presidencialismo; partidos políticos; coalizões; crise política.

\section{The Brazilian Political Crisis and the Institutional Debate}

\section{ABSTRACT}

The paper addresses the current Brazilian political crisis. It first discusses the return to traditional interpretations that see the combination between a presidential regime and a multiparty system as the main cause of the crisis. The paper criticizes this view and reasserts the more positive view about the Brazilian political system that merged from more recent scholarly work. As a conclusion, the paper notes the importance political strategies played in the current political crisis.

KEYWORDS: presidential regime; political parties; coalitions; political crisis.

[*] Universidade de São Paulo, São Paulo, SP, Brasil.E-mail: fplimongi@ gmail.com.

[**] Universidade do Estado do Rio de Janeiro, Rio de Janeiro, RJ, Brasil. E-mail: argelina@iesp.uerj.br.

[1] Ver Melo e Pereira (2013) e Alstonetal. (2016) para resenhas críticas.

\section{INTRODUÇÃo}

A crise atual reabriu o debate institucional. Para muitos, os problemas políticos enfrentados pelo país desde a reeleição da presidente Dilma Rousseff mostrariam o equívoco do "otimismo" que dominou a produção acadêmica brasileira sobre o funcionamento dos governos até então. ${ }^{1} \mathrm{O}$ impedimento da presidente e as dificuldades enfrentadas por seu sucessor, Michel Temer, apontariam para a inviabilidade do presidencialismo de coalizão. 
A conjuntura atual deu nova voz ao diagnóstico negativo que dominou a produção acadêmica ao longo da transição à democracia e nos primeiros anos do novo regime. As investigações da Lava Jato teriam revelado o custo do presidencialismo de coalizão ou, mais exatamente, o preço pago pelo Executivo para obter apoio parlamentar. Um alto preço que sempre esteve presente, mesmo nos momentos de "bonança", um custo nem sempre visível, mas que as investigações estariam revelando que teria "estado lá" o tempo todo. Bem consideradas as coisas, seguindo essa linha de raciocínio, a "cooperação" entre os poderes teria se resumido a poucos períodos do governo de Fernando Henrique Cardoso e de Lula, repousando, em última análise, nas qualidades excepcionais desses líderes para manter o Congresso sob seu controle.

Boa parte dessa discussão gira em torno do que estaria por detrás do funcionamento do presidencialismo de coalizão ou, mais concretamente, das bases sobre as quais presidentes formam e governam apoiados por coalizões partidárias no Brasil.

O termo-presidencialismo de coalizão-ganhou elasticidade e plasticidade próprias aos rótulos que passam a ser aplicados para caracterizar realidades complexas e dinâmicas. A conotação inicial dada ao termo por Sérgio Abranches era claramente negativa, visando descrever uma realidade anômala e instável, quando não inviável, em razão, fundamentalmente, do fato de a coalizão carecer de bases partidárias. Na realidade, na visão original, a fragilidade dos partidos brasileiros seria uma das dificuldades intransponíveis à formação de uma base de sustentação ao presidente.

Em meados dos anos 1990, o termo ganhou conotação mais neutra quando não positiva. Neutra porque se constatou que o fato de que presidentes sejam apoiados por coalizões não é algo anômalo ou singular. Positiva porque conferia estabilidade ao sistema político brasileiro. Nessa revisão, a reversão da avaliação dos partidos desempenhou papel crucial.A coalizão associada ao presidencialismo operaria em bases partidárias.

Por algum tempo, a segunda imagem chegou a sobrepujar a primeira. Ainda assim, a cada crise política, a ambiguidade e elasticidade dos termos permitia um retorno à formulação original, frisando-se a anomalia e a tendência à instabilidade. Na realidade, o eixo central do diagnóstico original nunca foi inteiramente abandonado: o sistema político brasileiro estaria fadado à crise. $\mathrm{O}$ conflito entre os dois poderes seria inerente ao arranjo institucional. A visão segundo a qual o poder legislativo seria um obstáculo a ser transposto e que só seria possível fazê-lo recorrendo a meios e/ou em condições excepcionais nunca foi inteiramente abandonada.

A coalizão seria um desses meios. Entretanto, a montagem da coalizão tende a ser vista como um ato de "compra", um pagamento feito 
pelo chefe do Executivo para obter a governabilidade, pagamento que teria como consequência o desvirtuamento do programa de governo. O modelo estaria na raiz da atual crise, e esta apenas evidenciaria que o modelo teria encontrado seus limites, que somente com o abandono do presidencialismo de coalizão ou, no mínimo, com sua transformação radical, seria possível sair do buraco em que o país se meteu.

Colocado nesses termos, o debate se torna necessariamente vago. Compara-se realidade a uma possibilidade, a um sistema que funcionaria em bases radicalmente diversas caso uma "verdadeira reforma política" fosse aprovada. As esperanças dos reformistas flutuam entre modificações do modelo eleitoral (abandono da representação proporcional de lista aberta), da forma de governo (adoção do parlamentarismo) ou ambos. Entretanto, a nosso juízo, o que permanece por demonstrar é que o presidencialismo de coalizão, de uma forma ou de outra, esteja na raiz da crise experimentada, a atual ou as anteriores.

Não resta dúvida que, no Brasil, as três coisas-crises, presidencialismo e coalizões - coexistem. Uma relação causal, contudo, como todos sabem, pede mais do que a ocorrência simultânea. Para que exista uma relação de causa e efeito seria preciso admitir que se a variável presidencialismo de coalizão assumisse "valores" ou formatos alternativos, a crise abrandaria. Mas o que precisaria variar? Qual seria o modelo alternativo ao presidencialismo de coalizão? Além disso, qual a verdadeira raiz do problema, o presidencialismo ou a coalizão?

O parlamentarismo, desde a redemocratização e ainda hoje, é visto como uma das soluções. Entretanto, no Brasil, dificilmente será possível ter um regime parlamentarista em que eventuais primeiros-ministros não sejam forçados a recorrer a coalizões. O parlamentarismo de coalizão seria muito diverso do presidencialismo de coalizão? Por quê?

Existem países em que há presidencialismo e não há coalizão. Portanto, é possível imaginar que o Brasil possa vir a ter um presidencialismo com governo unipartidário. Possível, mas nada fácil de produzir. Há limites para engenharia institucional. Assumamos queo Brasil passe a ter um sistema bipartidário e que venha a ser uma possibilidade real ter presidentes com maioria parlamentar. Seria diferente do que temos hoje? Por quê?

Outras tantas combinações são possíveis, mas não nos parece que a crise atual tenha gerado um debate institucional consequente, ainda que o parlamentarismo (ou semipresidencialismo) tenha sido resgatado pela trinca Michel Temer-José Serra-Gilmar Mendes. Interpretada como ato politicamente inconsequente que visava desviar as atenções das dificuldades do governo, a proposta sequer foi tomada como séria ou como tendo chances reais de sucesso. 
Assim, o debate político é povoado por referências à reforma política, sem que propostas concretas sejam trazidas ao debate. Tudo é muito vago. Fala-se constantemente na necessidade de mudanças institucionais sem que os efeitos desta ou daquela mudança sobre os problemas identificados sejam trazidos ao debate.

Em suma, os dois termos que compõem a hoje célebre expressão, tanto "presidencialismo" como "coalizão", podem variar. Assim, para o debate institucional, para o debate sobre possíveis reformas institucionais, a pergunta a ser feita pede precisão: o que precisa ser mudado? Como ter certeza que a mudança pregada alteraria o modus operandi da política brasileira que se acredita ser capturado nas eternas referências ao presidencialismo de coalizão?

No que segue, procuramos enfrentar essa discussão. O texto está organizado da seguinte forma. Na seção seguinte, apresentamos a versão negativa atual do presidencialismo de coalizão, buscando identificar quais seriam seus traços constitutivos e vínculos com a versão canônica do termo. Como argumentaremos, a elasticidade do termo permite que ele opere como um mutante, que ganha acentos e mesmos significados diversos, ao tempo que preserva seu traço crítico e negativo. Na terceira seção retomamos os argumentos acadêmicos correntes sobre o "presidencialismo da coalizão", para usar a variante cunhada por Andréa Freitas. Frisamos os aspectos institucionais que embasam o funcionamento do sistema político brasileiro consagrado pela Carta de 1988. A quarta seção é dedicada a apresentar uma visão não institucional para a crise atual. Para parafrasear o jargão, nosso ponto é: estratégias importam. A quinta seção apresenta uma breve conclusão.

\section{PREsidenCIALISMO de COALIZÃo}

O termo, já faz algum tempo, extravasou a academia. Aos poucos, ganhou contorno de um conceito ou intepretação sintética de uma realidade política que flutua entre a anomalia e a singularidade. Os elementos descritivos e interpretativos se fundiram, passando a requerer análise exegética capaz de lhe revelar a essência. Não por acaso, como mostramos adiante, o próprio criador do termo, em mais de uma oportunidade, engajou-se na empreitada. O presidencialismo de coalizãoé como uma esfinge à espera de quem a decifre.

Em lugar de recorrer à exegese do texto original ou embarcarmos em considerações teóricas, acreditamos que, para o presente trabalho, é mais adequado e útil recolher menções ao termo, ver como ele é empregado e o significado que lhe é atribuído.

Em editorial recente, de 14 de agosto de 2017, O Estado de São Paulo assim definiu o "conceito": 
[2] Spektor, 2017, p. 2 .

[3] Bersch; Praça; Taylor, 2013, p. 7, tradução nossa.

[4] Bersch; Praça; Taylor, 2013, p. 8 , tradução nossa.
Enquanto o presidente legisla, o Congresso governa-é assim que funciona o chamado "presidencialismo de coalizão". Nesse sistema bem brasileiro, o chefe de governo é obrigado a lotear o Executivo entre os partidos cujo apoio pretende obter.

No mea culpa do PSDB, em seu último programa partidário transmitido pela TV (17/08/2017), o partido fez uma autocrítica da sua adesão ao governo Temer, reconhecendo que "errou" ao aceitar as regras do que chamou

presidencialismo de cooptação [...] quando um presidente tem que governar negociando individualmente com políticos ou com partidos que só querem vantagens pessoais, que não pensam no país, uma hora apoiam, outra não, e, quando apoiam, cobram caro [...].

Em coluna publicada na Folha de São Paulo (20/07/2017), Matias Spektor mobiliza argumentos similares para caracterizar o modus operandi do sistema político brasileiro ao afirmar que

um presidente brasileiro só consegue governar distribuindo oportunidades de negócios aos partidos que o apoiam e cultivando uma elite empresarial que vive de trocar privilégios por financiamento de campanha e pagamento de propinas à base aliada. Para governar, nossos presidentes são obrigados a transformar o Planalto no QG da falcatrua, recebendo empresários sedentos porfacilidades e distribuindo "boquinhas" aos partidos. ${ }^{2}$

Vale frisar alguns termos empregados: um sistema bem brasileiro, em que presidentes são obrigados a lotear cargos, enquanto os partidos querem em troca oportunidades para fazer negócios.

Esses são apenas alguns exemplos. Poderíamos encher páginase páginas de visões similares. Na produção acadêmica, mesmo quando lateral ou marginal ao tema em questão, não faltam menções desairosas ao presidencialismo de coalizão. Ao examinar a composição da burocracia federal, Bersch, Praça e Taylor afirmam que o presidencialismo de coalizão se caracteriza pela "barganha tácita para obter apoio legislativo de aliados políticos em troca da carta-branca para os ministros do governo".3 O significado da barganha é definido de forma mais precisa em outro trecho: "muitos órgãos da administração - e com eles seus orçamentos e contratos-são entregues a partidos aliados com um tácito fechar de olhos para potenciais irregularidades". 4 A caracterização mais sintética toma a forma de uma "barganha de Fausto": de uma "carta-branca" e da "cegueira proposital para com a má conduta" em contrapartida ao apoio legislativo. 
Na visão dos autores, essa seria uma manifestação particular do que Barbara Geddes chamou de o "dilema dos políticos": "o conflito enfrentado por políticos entre a necessidade de consolidar o apoio político no curto prazo e o objetivo de desenvolver a capacitação [do Estado] no longo prazo". $5 \mathrm{O}$ argumento, portanto, parte de uma decomposição dos políticos em dois grupos em razão dos seus horizontes temporais: alguns movidos pelos interesses de longo prazo, outros pelos de prazo curto. Mais especificamente, se a política fosse ditada apenas pelos interesses de longo prazo, se todos os políticos ampliassem o seu raio de ação, não seria necessário "lotear" a administração em busca de apoio político.Além disso, implicitamente, os dois grupos de atores dotados de perspectivas distintas são identificados a posições institucionais específicas. De um lado há o Executivo, que precisa de apoio para aprovar políticas de longo prazo; de outro, o Legislativo, que detém os votos necessários para aprovar tais políticas, mas ocupado por políticos que só se interessariam por ganhos de curto prazo.

Nas passagens transcritas chama atenção a falta de opção do chefe do Executivo, "obrigado" a lotear o Estado com partidos, uma verdadeira vítima da situação com que se defronta. Ainda que recorra a argumento cuja estrutura é invariante, a onda atual de condenação do presidencialismo de coalizão tem características próprias. Na tradução que lhe conferem Bersch, Praça e Taylor, o interesse de curto prazo dos parlamentares é equiparado a uma carta-branca para práticas ilícitas. ${ }^{6}$

Vale observar ainda que, nas passagens citadas, presidentes negociam com partidos, e não com parlamentares individuais. A mudança não deixa de ser significativa e em certa medida faz justiça ao termo: a coalizão é partidária. No diagnóstico original, o problema presidencial era ainda mais agudo, na medida em que se negava a possibilidade de que o presidente pudesse negociar com partidos. Abranches 7 acreditava que as bases da coalizão seriam os governadores, argumento atualizado por Abrucio e Samuels. ${ }^{8}$ Outros, como Ames, Mainwaring e Lamounier se referiam a interesses individuais dos parlamentares. 9

Outra mudança significativa diz respeito ao conteúdo da barganha ou mais especificamente aos objetivos (função de utilidade) dos membros da coalizão montada pelo presidente. O presidente quervotos, quer aprovar a sua agenda que, seguindo a formulação proposta por Barbara Geddes, seria voltada para o desenvolvimento de longo prazo. Mas o que querem os partidos?

Na versão atual, partidos que aceitam dar votos ao presidente o fazem para que, literalmente, possam descer ao inferno. Seus propósitos nunca foram os melhores. Os interesses variaram com o tempo:atraso, clientelismo, fisiologismo, patronagem e outros tantos termos nega-
[5] Bersch; Praça; Taylor, 2013, p. 8, tradução nossa

[6] Bersch; Praça; Taylor, 2013.

[7] Abranches, 1988 .

[8] Abrucio; Samuels, 1997.

[9] Ames, 2000; Mainwaring, 1991; Lamounier, 1987. 
tivos, mas que, de uma forma ou de outra, apontavam para a formulação (ou bloqueio) de políticas específicas dirigidas a grupos sociais ou clientelas eleitoras identificáveis. Como já defendemos em outras oportunidades, esses argumentos eram atualizações da velha formulação do conflito entre o moderno (representado pelo Executivo) e o atraso (representado pelo Legislativo). Hoje, nem isso. Partidos que forçam os presidentes a concessões perderam suas bases sociais. $O$ que pedem em troca do seu apoioé a defesa de seus interesses próprios e, em geral, não confessáveis. Pediriam e receberiam a liberdade para roubar. Nada além da carta-branca para colocar o Estado a serviço dos seus próprios interesses. Trocariam votos pelo direito à pilhagem.

Em última análise, a versão atual do argumento, ao conferir ênfase excessiva à exploração do Estado em proveito próprio acaba por desconsiderar a arena eleitoral. Em outras palavras, desconsidera-se que esses políticos detêm mandatos eletivos e que estes são submetidos ao crivo do eleitorado de forma regular. Como esses parlamentares se elegem e se reelegem? Pilharo Estadoé uma estratégia compatível apenas com perspectivas de curtíssimo prazo, um horizonte temporal que não compreende o próximo ciclo eleitoral.

O fato é que estamos falando de representantes que, queiram ou não seus detratores, obtiveram mandatos eleitorais. Além disso, para que a explicação fique de pé, políticos com os mesmos objetivos devem ocupar esses postos no próximo ciclo eleitoral. Em outras palavras, quando examinado com cuidado e rigor, o argumento, não fecha.

Tais juízos, portanto, estão embasados em uma visão altamente negativa da operação do mecanismo eleitoral e como este seleciona os ocupantes do poder legislativo. Na versão original do argumento, quando o Legislativo era identificado com a sobrevivência da sociedade tradicional, atribuía-se a ele a representação de um interesse social, um viés conservador, mas cujas bases, em última análise, estavam assentadas sobre o controle do eleitorado rural pelos proprietários de terra. No discurso atual, referências ao atraso e ao clientelismo persistem, mas perderam a sua referência social clara. No limite, o argumento acaba por afirmar que os políticos encastelados no Congresso, aqueles que precisam ser "comprados" pelo Executivo, não passam de representantes dos seus próprios interesses. Mas como obtêm mandatos?

$\mathrm{Na}$ realidade, tal argumento, quando levado ao seu limite lógico, pouco deve ao presidencialismo e à coalizão e, por isso mesmo, deixa inteiramente de ser institucional. Neste ponto, vale citar, o esclarecimento do criador sobre sua criatura:

Não creio que o clientelismo e o fisiologismo sejam intrínsecos ao padrão de governança. Eles são componentes do padrão de relacionamento entre 
partidos e eleitores, portanto um dado sociológico. Se os partidos majoritários logram conquistar esta maioria por meio deste tipo de mecanismo de manipulação do eleitor despossuído e não há alternativas competitivas em muitos redutos, a relação entre esta maioria legislativa e o Executivo terá, de fato, um elevado grau de propensão ao fisiologismo e ao clientelismo. Mas seria assim, se o governo não fosse de coalizão. ${ }^{10}$

A conclusão se impõe:

O problema não está, portanto, na relação entre Executivo e Legislativo que o presidencialismo de coalizão determina. Está na relação entre partidos e eleitores, que não está também associada às regras eleitorais, mas no nível de desenvolvimento cívico do eleitorado, entre outras coisas. ${ }^{11}$

Se, de fato, for assim, o debate não é institucional. Não há muito que se possa fazer para alterar esse estado de coisas. $O$ problema não estaria quer no presidencialismo, quer na coalizão, mas na sociedade. A despeito das referências a termos em voga na sociologia atual, o argumento não faz outra coisa senão desqualificar os eleitores brasileiros: tidos como carentes do "desenvolvimento cívico" para fazer escolhas e incapacitados, portanto, de punir os maus políticos. O problema estaria na "sobrevivência de redutos eleitorais" em que não haveria competição eleitoral e na "manipulação dos eleitores despossuídos".

Os ecos de velhos diagnósticos atestando a inviabilidade do governo representativo no Brasil são patentes. Volta-se à teoria da modernização, ainda que de forma diluída e adornada com novos termos mais condizentes com modismos recentes para amparar velhas teses moralistas e elitistas. Enquanto o eleitorado apresentar esse grau de desenvolvimento cívico, afirma quem cunhou o termo presidencialismo de coalizão, o problema persistirá.

\section{BASES INSTITUCIONAIS DA COOPERAÇÃO EXECUTIVO-LEGISLATIVO}

No presidencialismo consagrado na Constituição de 1988, não há possibilidade de bloqueio às propostas do presidente. Seus poderes legislativos - MPs, urgência e iniciativa exclusiva-lhe permitem forçar o voto sobre o que considerar prioritário. O Executivo tem enorme poder de agenda, nos seus dois sentidos, definição da agenda legislativa e influência sobre seus resultados. ${ }^{12}$ Poderes de agenda, contudo, não substituem a maioria, não permitem passar por cima do Congresso.

A maioria congressual sempre conta com a possibilidade de rejeitar propostas do presidente. Bloquear, entretanto, não é o mesmo que ter a capacidade de governar. A possibilidade de que uma maioria
[10] Abranches, 2001, p. 268.

[11] Abranches, 2001, p.269.
[12] Cox, 2000 . 
[13] Figueiredo; Limongi, 1995.

[14] Amorim Neto; Santos, 2003; Figueiredo; Limongi, 1995; 1999; 2007; Lemos, 2001; Ricci, 2003

[15] Inácio, 2006; Batista, 2013;Almeida, 2015; Freitas, 2016.

[16] Freitas, 2016.

[17] Martins, 2012; Cruz, 2009. congressual enfrente e submeta o presidente à sua vontade é pequena. Mesmo uma maioria capaz de aprovar medidas terá que se haver como veto presidencial e, tão ou mais importante, com o fato de o presidente controlar a execução orçamentária.

Já foi demonstrado que o Executivo é o principal legislador de jure e de facto do país. ${ }^{13}$ Os dados disponíveis permitem colocar de lado duas alternativas consideradas anteriormente: está claro que o Congresso não é a origem das propostas legislativas e, tampouco, paralisa o Executivo. Em resumo, não há crise de governabilidade ou paralisia decisória. O sistema político brasileiro produz decisões, e a origem destas tende a ser o Executivo.

A iniciativa dos legisladores, porém, não é nula. Se nos concentrarmos nas leis ordinárias, sobretudo as com maiores conteúdos sociais, a iniciativa legislativa dos parlamentares é significativa. Alguns dos primeiros artigos sobre o tema já demonstravam que, no que se refere a políticas sociais, a produção legislativa dos parlamentares rivaliza com a do Executivo. ${ }^{14}$

Além disso, o fato de o Executivo ser o propositor da maior parte das iniciativas transformadas em lei não implica que o Congresso seja alijado da produção legal. O estágio atual das pesquisas sobre o processo legislativo estabeleceu de forma inequívoca que o Congresso participa do processo legislativo de várias formas. ${ }^{15}$ Emendar os projetos propostos pelo Executivo é a mais direta e palpável dessas formas de participação. ${ }^{16}$

A constatação reabre, ou pode reabrir, a caixa de Pandora. Emendar um projeto pode ir de um mero adendo à desfiguração completa. Os estudos citados mostram que essa participação confere significado substantivo ao governo de coalizão. Isto é, que ao emendar as propostas oriundas do Executivo os partidos que integram a coalizão imprimem marcas próprias às políticas públicas.

Alterações do projeto original ao longo da tramitação legislativa, como mostram estudos de caso, longe de desfigurar projetos importantes para o Executivo, os corrige e aperfeiçoa. As emendas aprovadas, em geral, têm origem nos membros da própria coalizão. ${ }^{17} \mathrm{~A}$ inclusão de matérias alheias ao cerne dos projetos também ocorre, porém não com a frequência que o folclore político faz crer e, muitas vezes, com anuência do governo que, quando contrário às mesmas, as veta.

Em resumo, estudos recentes mostram que emendar a agenda proposta pelo Executivo é a norma. Mais do que isso, mostram a lógica de operação de um governo de coalizão. A iniciativa, a formulação e a proposição da agenda cabem ao Executivo, ao presidente ou ao seu partido. Os partidos da coalizão, em geral, colaboram com a implementação dessa agenda. Respeita-se assim o mandato popular que emerge das urnas. A versão final da agenda, aquela que é aprovada e 
que será implementada, cabe à coalizão. Negociações e concessões entre aliados são o "arroz com feijão" de governos multipartidários, no parlamentarismo e no presidencialismo.

A iniciativa legislativa, por força das prerrogativas constitucionais com que conta, cabe ao chefe do Executivo. Os líderes partidários, por sua vez, têm amplos poderes regimentais. Como membros da coalizão, podem usá-los, e de fato o fazem, para facilitar a tramitação de projetos do governo, restringir emendas da oposição ou, quando necessário, de parlamentares rebeldes, indicar e retirar membros das comissões permanentes etc. Sobretudo, membros da coalizão participam ativamente da produção legal, alterando, por meio do emendamento, as propostas feitas pelo poder executivo. Ou seja, na passagem pelo Congresso, dado o poder de agenda detido por líderes partidários, os membros da coalizão controlam o processo legislativo e influem na aprovação de medidas de interesse do governo.

Obviamente, se o governo não fosse de coalizão e se o presidente dispusesse de sólida maioria partidária no Congresso, o resultado poderia ser outro. Em uma situação extrema, as negociações e concessões se reduziriam a zero e a agenda seria aprovada tal como proposta. Se o resultado seria melhor é algo que não pode se assumir como ponto pacífico. Não faltam exemplos de políticas desastrosas ou de conflitos entre facções no interior de governos unipartidários. Como exemplo, basta olhar para a Argentina, onde o governo unipartidário da União Cívica Radical não impediu a crise econômica que levou à renuncia de Raúl Alfonsín meses antes do fim de seu mandato. O governo que o sucedeu, o do Partido Justicialista de Carlos Menem, tampouco foi um exemplo de unidade, muito menos de sucesso absoluto.

O fato é que, no Brasil, qualquer participação do Congresso no processo decisório tende a servista como negativa. Em geral, o Congresso é caracterizado como o reino do interesse menor, como o representante de "bancadas" de legitimidade questionável, como ruralistas, evangélicos e outros tantos grupos desconectados do que seriam, supostamente, os verdadeiros anseios e interesses da nação.

Do ponto de vista analítico, a qualificação dos grupos de interesse entre legítimos e ilegítimos é questionável. Qualquer julgamento depende da posição do juiz em relação aos interesses desses grupos e da análise do seu comportamento. Grupos de interesse têm objetivos diversos, competem entre si e chamam atenção para diferentes aspectos/dimensões de políticas públicas específicas, apontando os prós e contras envolvidos em cada decisão.

No frigir dos ovos, a decisão final é e será sempre política, cabendo às lideranças pesar prós e contras, fazer seus cálculos eleitorais, quantos votos ganham, quantos perdem e, ao fim dessas considerações, tomar suas decisões. Assim funcionam as democracias reais. 
Em governos de coalizão há que se considerar o papel dos partidos da base do governo e sua influência nos resultados do processo decisório e na formulação de políticas públicas. As políticas resultantes de governos de coalizão são as políticas da coalizão. ${ }^{18}$ Envolvem um compromisso entre o governo que propõe políticas e os partidos que o apoiam.

As versões negativas correntes desconsideram a participação dos partidos da coalizão na formulação e implementação das políticas. Como mostramos na seção anterior, tal visão se ampara em uma versão extremada do argumento de que a obtenção de cargos seria um fim em si mesmo, desconsiderando o imperativo eleitoral que pesa sobre políticos. No argumento corrente, as carreiras dos parlamentares estariam asseguradas quaisquer sejam as políticas que patrocinem, uma vez que se dá como assentado que seriam eleitos em redutos não competitivos ou recorrendo a meios escusos. Mais do que isso, quando passam a apoiar o governo, o único objetivo seria assegurar os ganhos que o controle sobre a máquina do Estado lhes asseguraria.

Há muito a premissa de que políticos visam apenas cargos foi abandonada pela ciência política. Há que se considerar que políticos visam também votos e policies. Afinal como se apresentam e se comunicam com o eleitorado? Como são eleitos?

A inconsistência do modelo é patente. Políticos não enfrentariam qualquer limitação em suas opções. Não há custos, só benefícios. O fato é que há uma decisão política a tomar, isto é, fazer parte do governo não traz apenas benefícios. Se fosse assim, por que alguns partidos ficam de fora do governo? Integrar o governo envolve tanto ganhos quanto perdas. Assumir responsabilidade pelas políticas, a identificação com o governo, porvezes, traz ganhos, porvezes traz perdas, como o atual "drama" dos tucanos deixa claro: há os que querem ser parte do governo e os que querem integrar a oposição, pois cada grupo avalia de forma diversa as consequências de se atrelar ao governo Temer.

Vale observar que no argumento original de Linz, o presidencialismo seria incompatível com governos de coalizão em razão do cálculo eleitoral dos partidos que não controlam a presidência. Entre participar do governo ou apostar na vitória no próximo ciclo eleitoral, partidos optariam pela segunda opção. Ser governo só traria perdas. Aestratégia racional, segundo Linz, seria a irresponsabilidade política.

A lógica que dita a formação de governos de coalizão em sistemas parlamentaristas se estende aos presidencialistas. Para alguns partidos, a melhor estratégia pode ser não participar, dissociar-se das políticas implementadas pelo governo, na espera de serem recompensados pelo eleitorado. Para outros, a opção de entrar para o governo é vista como superior à espera da próxima eleição, seja para influenciar políticas que gerariam bons resultados eleitorais ou por não ter expectativa de conquistar o poder executivo. 
O fato é que entrar para o governo envolve custos. Mais do que isso, os ganhos dependem do desempenho do próprio governo que passam a integrar, senão de todo o governo, ao menos do ministério que assumem. Para dizer de forma direta: usar os ministérios que assumem única e exclusivamente para desviar recursos para os próprios bolsos não é uma estratégia eleitoral consistente. De uma forma ou de outra, as políticas que patrocinam precisam render dividendos eleitorais. Mesmo que recorram a práticas clientelistas e fisiológicas, tais práticas não emergem naturalmente, sem o desenho e a implementação de políticas com este fim.

Afirmar que coalizões envolvem custos não passa da constatação do óbvio. Presidentes minoritários raramente conseguiriam aprovar suas propostas e, por isso mesmo, formam uma coalizão. Sabem que seriam derrotados se não contarem com o apoio da maioria, e porque antecipam sua derrota, presidentes (tanto quanto primeiros-ministros) recorrem à formação de coalizões. Em outras palavras, a formação de uma coalizão não é nada mais nada menos que a aplicação da famosa lei da antecipação das reações.

Os partidos,em geral, buscam ocupar ministérios quelhes permitam influenciar políticas em torno das quais construíram a sua reputação, reforçando seus vínculos com o eleitorado ou com financiadores de campanha, prática, uma vez mais, comum também no parlamentarismo.19

Sejam quais forem as motivações dos diferentes partidos (cargos, políticas públicas ou votos), em governos de coalizão o processo legislativo agrega mais informação à tomada de decisões. Em governos unipartidários, decisões são tomadas entre quatro paredes. O partido que controla o governo não tem interesse em expor as diferentes visões e dissensões no seu interior, pois dar mostras de divisão o enfraqueceria diante do público.

No sistema brasileiro, os líderes partidários detêm também considerável poder de agenda e controle sobre o processo legislativo, o que lhes permite solucionar os problemas de coordenação dos deputados e, com isso, servir de ponte entre as bancadas que compõem a maioria no Legislativo e no Executivo. Dessa forma, as barganhas entre o Executivo e o Legislativo são estruturadas em torno dos partidos. A possibilidade de o presidente impor a sua agenda sem a cooperação dos líderes é zero. Partidos, portanto, são atores coletivos relevantes no processo legislativo. Os incentivos para a cooperação em bases partidárias são altos. Os poderes de agenda facilitam o funcionamento da coalizão nos moldes enfatizados por Huber $^{20}$ e recuperados pelos nossos trabalhos. Ou seja, em governos de coalizão, mais do que uma relação vertical de conflito entre Executivo e Legislativo, observa-se uma relação horizontal de barganha e cooperação entre o Executivo e os membros da coalizão.
[19] Ver Laver e Shepsle (1994; 1996).

$$
\text { [20] Huber, } 1996 .
$$


A insistência de que a crise teria bases institucionais, mais especificamente, que seria uma consequência das escolhas institucionais fundamentais (presidencialismo e representação proporcional) acaba por fazer tábula rasa da especificidade das condições enfrentadas. Nem todas as crises têm as mesmas causas, e, muito menos, o remédio a todas deve ser o mesmo.

A falta de rigor analítico das explicações institucionalistas tradicionais fica patente quando os impedimentos de Collor e de Dilma são equiparados e tratados como manifestações dos mesmos impasses. As evidências mobilizadas, entretanto, apontam em direções radicalmente opostas. O governo Collor, em geral, é apresentado como a comprovação de que presidentes que enfrentam o Congresso e formam coalizões minoritárias não teriam como governar. Analistas não se cansam de lembrar a fragilidade do partido de Collor, o PRN, fundado às pressas e sem cadeiras legislativas. Mobiliza-se, neste caso, o modelo original apresentado por Linz em sua inteireza. Separação de poderes engendraria um conflito entre interesses inconciliáveis. Dilma, entretanto, sempre contou com uma ampla coalizão a apoiá-la. Nos diagnósticos atuais, o problema seria o inverso. Hoje, partidos estariam sempre prontos a ser parte do governo, a pedir e explorar o seu quinhão. Assim, enquanto o impeachment de Collor teria se dado por sua incapacidade de formar uma coalizão majoritária, o de Dilma teria sido pelos seus excessos.

Atribuir causas institucionais à crise atual é desconsiderar as diversas dimensões que se cruzam e se alimentam para lhe conferir especificidade e, sobretudo, pede que se deixe de lado a polarização política que se armou ao longo das disputas presidenciais e dos governos petistas. Polarização esta que foi alimentada e ganha força nos momentos finais do processo eleitoral de $2014 \mathrm{em}$ meio a uma série de revelações de corrupção. De outro, ganha corpo uma crise econômica que acentua e interage com a crise política.

Com a quarta vitória consecutiva do PT, depois de seis eleições disputadas com o PSDB, este contestou o resultado eleitoral, solicitando a recontagem dos votos. Em um primeiro momento, o recurso foi negado pelo TSE, fiador até então inconteste da lisura do processo eleitoral. Em si mesma, a simples apresentação do questionamento, sobretudo quando se leva em conta a fragilidade das evidências apresentadas, pode ser tomada como um indicador do ânimo dominante entre os derrotados. Em fevereiro de 2015 , começam a circular as primeiras versões de pedidos de impedimento da presidente que, segundo noticiário da imprensa, teriam sido gestadas em círculos próximos a líderes do PSDB. Em meio a essas contestações, o ministro Gilmar 
Mendes, então vice-presidente do Superior Tribunal Eleitoral, em diversas oportunidades, manteve viva a suspeita de que a prestação de contas da chapa vencedora poderia não ser aprovada, contribuindo assim para alimentar dúvidas sobre o resultado proclamado.

A contestação dos resultados eleitorais caminha paripassu à montagem de uma ampla coalizão extraparlamentar. Alimentada pelas investigações da Operação Lava Jato, que apontam para o envolvimento do governo e, por conseguinte, do PT em desvio de recursos públicos, o movimento ganha as ruas, aumentando a pressão sobre o governo.

O PSDB, nesse quadro, como de resto já acontecera durante o processo eleitoral, vê ameaçada a sua capacidade de liderar a coalizão oposicionista. O ritmo dos protestos de rua contra o governo, por exemplo, foi ditado por movimentos como o Vem Pra Rua e o Movimento Brasil Livre (MBL). Muitas vezes, os líderes desses movimentos, rechaçaram a adesão de políticos tucanos aos protestos convocados.

A primeira grande manifestação contra o governo se deu em março de 2015 , e outras se seguiram durante o ano, além dos panelaços a qualquer ação pública da presidente. $\mathrm{O}$ apoio mais conspícuo entre as "classes produtoras" veio da Federação das Indústrias do Estado de São Paulo(Fiesp), mas ela não foi exceção.Aoposição, portanto, adotou uma posição radical, partindo para o confronto e para o questionamento da legitimidade do mandato presidencial conquistado nas urnas.

Ao mesmo tempo, crescia a insatisfação de amplos setores da população com as perdas provocadas pelo baixo desempenho da economia em razão dos erros cometidos pelo governo para manter o ritmo de crescimento alcançado nos anos anteriores. A crise econômica faz cessar o processo de redistribuição de renda que havia ganhado força nas administrações anteriores, contribuindo de forma decisiva para a queda abrupta de popularidade da presidente.

O fato é que o segundo governo Dilma se mostra incapaz de propor políticas para debelar a crise econômica, agravando ainda mais o quadro. Na realidade, indeciso e incapaz de formular uma política consistente, o governo acabou sendo bombardeado pelos dois lados, tanto pela direita quanto pela esquerda.

Para além da oposição, o governo Dilma enfrentava dificuldades em seu próprio campo, tanto em sua relação com o PT quanto com os partidos que formavam a sua base de apoio, em especial com o PMDB, cuja ação, como se sabe, sob a batuta da dupla Temer-Cunha, seria decisiva para o encaminhamento final da crise do governo Dilma.

Ainda assim, não se pode desconsiderar as relações do governo com o PT, mais especificamente que a postura do governo diante da crise econômica e da Lava Jato leva ao estremecimento das relações entre o partido e o governo. Na economia, Dilma se movera para a direita, convocando Joaquim Levy para enfrentar a criseeconômica; mas como 
não completa o movimento, fraquejando em momentos chaves, acaba perdendo nos dois lados. Não conquista a direita (se é que, naquele momento, ela ainda poderia ser conquistada) e cria arestas dentro do PT, que a critica por abandonar o comprometimento com a causa popular. Não faltam líderes de movimentos sociais ameaçando o governo com protestos e outras manifestações contra a política econômica neoliberal de Levy.

No capítulo Lava Jato, não foram poucos os próceres do PT a criticar o governo por deixar que a Polícia Federal perseguisse o partido. Não importa saber se o governo tinha ou não meios de controlar a Operação Lava Jato, importa que a maior parte dos petistas acreditava que a possibilidade existia. Mais que isso, para os petistas, o fato de tais medidas não terem sido adotadas significava um "descaso governamental", para dizer o mínimo, para com a sorte do partido e de seus principais líderes.

Em outras palavras, a liderança de Dilma, sua fidelidade ao partido, aos seus ideais e programa foram questionados. Não por acaso, ganhou força o contraste com a liderança de Lula, cuja sombra nunca deixara de obscurecer a presidente. Com o tempo, se consolida entre petistas a ideia de que ter apoiado a reeleição de Dilma em lugar de promover o retorno de Lula havia sido um erro, um erro fatal. Não por acaso, dar um ministério ao ex-presidente, deixando que assumisse reponsabilidades próximas à de um primeiro-ministro, crescentemente passou a ser visto como a alternativa para salvar a presidente, $\mathrm{o}$ governo e o PT de um desastre que, por inúmeras razões, parecia cada vez mais iminente.

$\mathrm{Na}$ realidade, não seria exagero afirmar que, para muitos petistas, preservar o ex-presidente, isolando-o das investigações e de possíveis condenações, sempre foi prioridade número um. O próprio ex-presidente, na realidade quando instado a aceitar a pasta ministerial, hesita em mais de uma oportunidade.

No front legislativo, o segundo mandato de Dilma se iniciou com a disputa entre o PT e o PMDB pela presidência da Câmara. A vitória de Eduardo Cunha azedou ainda mais as relações do governo com seu maior aliado e com sua base parlamentar. Após infringir derrota humilhante ao governo, o deputado carioca passou a ser incensado por setores da oposição extraparlamentar que o elevam a posição de liderança capaz de fazer frente ao PT. De forma hábil, Cunha mantém relação ambígua com o governo, com quem não rompe, mas a quem não se cansa de criticar, colocando-se sempre como uma alternativa para eleições futuras.

Entretanto, para além desse jogo de cena, a relação de Cunha com o governo é ditada pelas investigações da Lava Jato. O deputado carioca é o primeiro "peixe grande" a se enredar seriamente nas investigações, 
e, à medida que seus problemas se agravam, suas relações com o governo Dilma se tornaram cada vez mais tensas e conflitivas. O recurso a ameaças e, quando não, à pura chantagem para obter proteção são armas a que Cunha recorre sem maior cerimônia. Assim, quando viu seu mandato ameaçado, rompeu com o governo e partiu para o ataque, usando das prerrogativas do seu cargo para afastar a presidente.

As ações de Cunha tiveram um único objetivo: obter proteção para ele e para seu grupo. Com a denúncia contra ele aceita pelo Supremo Tribunal Federal e um processo de cassação no Conselho de Ética da Câmara, o presidente da Câmara acolheu, em dezembro de 2015, um dos muitos processos que pediam o impedimento da presidente. Não por acaso, um processo que contara com sua "assessoria informal". Originalmente, a solicitação estava ancorada nas denúncias de corrupção. Sob a orientação de Cunha, as "pedaladas fiscais" passam a ser a mola mestra do pedido. Além disso, para ganhar mais força e respeitabilidade, após aconselhamento de Cunha, o pedido ganhou a assinatura de um jurista historicamente associado ao PT. Em outras palavras, Cunha propôs um acordo à oposição radicalizada. Ofereceu a cabeça de Dilma para se salvar. A proposta foi prontamente aceita.

A despeito do discurso moralista que o cercou e das inúmeras referências aos resgates dos ideais republicanos feitas em praça pública, o processo de impeachment de Dilma foi comandado por políticos cuja associação e participação em esquemas de corrupção era notória. Para esse grupo, o impedimento de Dilma não passou de uma operação de resgate. Com Dilma no poder, não seria possível deter a Lava Jato. Livres da presidente, como afirmou Romero Jucá em conversa com Sérgio Machado, seria possível "estancar a sangria", "traçar um círculo", distinguindo os já caídos dos que seriam salvos.

As desventuras do governo de Michel Temer, enredado de forma direta pelo desdobramento das investigações, mostram que a corrupção não é uma marca exclusiva do PT, muito menos o resultado do seu alegado "projeto hegemônico de poder". Acreditou em pontes lançadas em direção ao futuro quem quis acreditar que, se livrando do PT, o país se veria livre da corrupção, ou melhor, não enxergou que tinha diante de si uma pinguela cujas fundações eram frágeis e superfaturadas. Não por acaso, os movimentos sociais em prol da moralização da política deixaram as ruas e não mostraram um pingo de indignação quando o governo atual foi denunciado.

A crise do segundo governo Dilma que levou a seu impeachmente se arrasta ao longo da presidência de Temer, portanto, não tem causas institucionais. Dependeu, basicamente, da estratégia dos atores políticos. O seu grande artífice e comandante foi Eduardo Cunha, cujos interesses e passado eram conhecidos. Os beneficiários diretos do impeachment, Temer e seu grupo íntimo, nunca pautaram seu compor- 
tamento político pelo apreço a ideias e à boa gestão da coisa pública. Aceitou a liderança desse grupo quem fez do afastamento do PT do poder a prioridade número um. Pode-se debater quem usou quem nessa aliança, mas o fato é que Temer, Cunha e outros tantos fizeram uso da mobilização anti-PT para chegar ao poder e, dessa forma, aumentar suas chances de escapar das denúncias que os ameaçavam.

\section{CONCLUSÃo}

Ao longo da crise, a corrupção passou a ser identificada com o presidencialismo de coalizão como o preço a ser pago pelo presidente para obter apoio parlamentar. Como dissemos anteriormente, as duas coisas coexistem, coalizões e corrupção, mas há uma enorme distância entre coexistência e causalidade. A suposição é que os partidos que integram a coalizão só aceitariam fazê-lo se recompensados com a carta-branca para incorrer em práticas ilícitas.

O papel dos partidos e, portanto, da coalizão no argumento não é tão claro quanto se pretende. Assume-se que a necessidade de apoio, a busca da maioria, colocaria o presidente nas mãos dos partidos encastelados no Congresso. Entretanto, por que seria diferente se o partido do governo controlasse a maioria das cadeiras legislativas? Por exemplo, se o PMDB, hoje, sob Temer, tivesse maioria, mudaria alguma coisa? Não é certo que mudaria para o melhor. Note-se que para os que associaram o PT à corrupção e a um projeto de poder hegemônico, a mesma objeção se aplicaria. Um governo unipartidário do PT seria melhor? Em outras palavras, o presidencialismo de coalizão leva a culpa, mas não é claro que os críticos tenham em mente quer o presidencialismo, quer o fato deste ser de coalizão quando o colocam como a raiz dos problemas políticos do país.

$\mathrm{O}$ argumento, portanto, se trocado em miúdos, implica em um retorno à tese da irresponsabilidade do Legislativo e da falta de compromisso com princípios e programas que caracterizaria os políticos brasileiros. Em contraposição, o Executivo, sem que necessariamente se dê conta disso, acaba sendo elevado à posição de defensor dos interesses gerais. Ao fim e ao cabo, nesse argumento, o presidente, Dilma ou Temer, não importa quem exerça o cargo, é sempre retratado como uma vítima.

Nessa crítica, há muito pouco de verdadeiramente institucional. Quando muito se afirma que as motivações e o comportamento dos atores seriam uma decorrência direta do sistema de governo. No parlamentarismo, quando formam governos, primeiros-ministros buscariam obter com o apoio de parlamentares fiéis a partidos programáticos. No presidencialismo, a coisa seria radicalmente diferente, maiorias só seriam formadas por meio da distribuição de benesses e 
a tolerância com atos ilegais. Parlamentares, neste caso, são equiparados a chantagistas.

Essa visão fere a regra básica da análise dos efeitos de instituições que requer que premissas motivacionais e comportamentais sejam as mesmas em diferentes arranjos institucionais. Em mundos povoados com atores com motivações distintas, programáticos em um deles, chantagistas no outro. Não é de se estranhar, portanto, que se conclua que o primeiro é mais belo que o segundo.

Mesmo no argumento alegada ou supostamente institucional, a corrupção e a crise que o país vem enfrentando pouco têm a ver com o desenho institucional. Reconhecer que instituições importam não é o mesmo que dizer que só instituições importam. Não há sistema político imune a crises. Não há sistema político que funcione sem que políticos façam escolhas, definam seus objetivos e estratégias para lidar com seus aliados e seus inimigos. Eessas escolhas têm consequências, nem sempre as melhores ou aquelas com as quais concordemos. Em uma palavra, não há sistema que prescinda da política.

FERNANDO LIMONG I é professor titular do Departamento de Ciência Politica da USP, pesquisador sênior do Cebrap e pesquisador do CNPq e do Neci-USP.

ARgELina Cheibub Figueiredo é professora do Iesp-Uerj, pesquisadora sênior do Cebrap e pesquisadora do CNPq.

Os autores têm longa história de colaborações e pesquisas conjuntas sobre o tema. São os coordenadores de projeto temático da Fapesp cuja existência se estende por mais de duas décadas. Em razão dessa longa colaboração, já publicaram dois livros e mais de uma dezena de artigos sobre o sistema político brasileiro.

\begin{tabular}{l} 
Recebido para publicação \\
em 31 de agosto de 2017. \\
\hline Aprovado para publicação \\
em o9 de novembro de 2017. \\
NOVOS ESTUDOS \\
CEBRAP \\
109, novembro 2017 \\
Pp.79-97
\end{tabular}

\section{REFERÊNCIAS}

Abranches, Sérgio. "Presidencialismo de coalizão: o dilema institucional brasileiro". Dados, v. 31, n. 1, pp. 5-34, 1988.

. "A democracia brasileira vai bem, mas requer cuidados". In: Velloso, João Paulo dos Reis (Org.). Comovãoo desenvolvimento e a democracia no Brasil? Rio de Janeiro: José Olympio, 2001. pp. 251-278.

Abrucio, Fernando; Samuels, David. “A nova política dos governadores". Lua Nova, n. 40/41, pp.137-166, 1997.

Almeida, Acir. "Processo legislativo: mudanças recentes e desafios”. Boletim de Análise Político-Institucional, Brasília, Ipea, n. 7, pp. 44-50, jun. 2015 .

Alston, Lee J. et al. Brazil in Transition:Beliefs, Leadership, and institutional Change. Princeton: Princeton University Press, 2016.

Ames, Barry. The Deadlock of Democracy in Brazil.Ann Arbor: University of Michigan Press, 2000.

Amorim Neto, Octavio; Santos, Fabiano. "O segredo ineficiente revisto: o que propõem e o que aprovam os deputados brasileiros". Dados, v. 46, n. 4, pp. 661-698, 2003.

Batista, Mariana. “O poder no Executivo:uma análise do papel da Presidência e dos Ministérios no presidencialismo de coalizão brasileiro (1995-2010)". Opinião Publica, v. 19, n. 2, pp.449-473, nov. 2013.

Bersch, Katherine; Praça, Sérgio; Taylor, Matthew. "State Capacity and Bureaucratic Autonomy Within National States: Mapping the Archipelago of Excellence in Brazil". Paper prepared for presentation at The Latin American Studies Association Conference, Washington D. C. 2013.

Cox, Gary. “On the Effects of Legislative Rules”. Legislative Studies Quarterly, v. 25, n. 2, pp. 169-192, maio 2000.

Cruz, Márcia Rodrigues da. Legislativo transformador? As modificações do Legislativo nos projetos de lei do Executivo. Dissertação (mestrado) — Universidade Cândido Mendes; Centro de Formação da Câmara dos Deputados, Brasília, 2009.

Figueiredo, Argelina; Limongi, Fernando. "Mudança constitucional, desempenho do Legislativo e consolidação institucional". Revista Brasileira de Ciências Sociais, n. 29, pp. 175-200, 1995.

. "Congresso doce. Executivo amargo". Insight-Inteligência, v. 2, n. 8, pp. 8-18, 1999. 
. "Instituições políticas e governabilidade: desempenho do governo e apoio legislativo na democracia brasileira”. In: Ranulfo; Carlos; Alcântara, Manuel (Orgs.).A democracia brasileira:balanço e perspectivas para o século 21. Belo Horizonte: Ed. UFMG, 2007. pp.147-198.

Freitas, Andréa M.Opresidencialismo da coalizão, Rio de Janeiro: Fundação Konrad Adenauer, 2016.

Huber, John D. Rationalizing Parliament. Cambridge: Cambridge University Press, 1996.

Inácio, Magna. Presidencialismo de coalizão e sucesso presidencial na esfera legislativa (1990-2004). Tese (doutorado)_ Universidade Federal de Minas Gerias, Belo Horizonte, 2006.

Lamounier, Bolivar. "Perspectivas de consolidação democrática: o caso brasileiro". Revista Brasileira de Ciências Sociais, v. 2, n. 4, jun. 1987 .

Laver, Michael; Shepsle, Kenneth A. (Orgs.).Cabinet Ministers and Parliamentary Government. Cambridge: Cambridge University Press, 1994.

.Making and Breaking Governments. Cambridge: Cambridge University Press, 1996.

Lemos, Leany. 2001. "O Congresso brasileiro e a distribuição de benefícios Sociais no período 1988-1994: uma análise distributivista". Dados, v. 44, n.3,pp.561-605, 2001.

Mainwaring, Scott. "Politicians, Parties, and Electoral Systems: Brazil in Comparative Perspective". Comparative Politics, v. 24, n. 1, pp. 21-43, out. 1991.

Martins, Ricardo Chaves de Rezende. Opoderlegislativo e as políticas públicas educacionais no período 1995-2010. Brasília: Câmara dos Deputados; Edições Câmara, 2012. (Série Memória e Análise de Leis, n.3.)

Melo, Marcus André; Ng'ethe, Njuguna; Manor, James.Against the Odds: Politicians, Institutions and the Fight against Poverty. Nova York: Columbia University Press, 2012.

Melo, Marcus André; Pereira, Carlos. Making Brazil Work: Checking the President in a Multiparty System. Nova York: Palgrave MacMillan, 2013.

Ricci, Paolo. “O conteúdo da produção legislativa brasileira: leis nacionais ou políticas paroquiais?”. Dados, v. 46, n. 4, pp. 699-734, 2003.

Spektor, Matias. "Instável". Folha de São Paulo, Caderno Poder, p. 2, 20/jul./2017. 